\title{
RURALITY AND THE PROFESSIONAL DEVELOPMENT OF UNIVERSITY TEACHERS
}

\section{Ndebele}

School of Teacher Education and Training

North West University; Mafikeng Campus

Mafikeng, South Africa

e-mail: clever.ndebele@nwu.ac.za

\section{P. Muhuro*}

e-mail: pmuhuro@ufh.ac.za

\section{Nkonki*}

e-mail:vnkonki@ufh.ac.za

*Teaching and Learning Centre

University of Fort Hare

Alice, South Africa

\section{ABSTRACT}

This study forms part of a wider NRF project that sought to examine the enabling and constraining conditions in the uptake of professional development opportunities by academics as teachers at eight South African universities. This case study isolated two rurally-based, historically disadvantaged South African institutions (HDIs). Qualitative data from institutional self-evaluation reports were augmented with semi-structured interviews conducted with five members of the senior management and ten academics at each of the institutions. Thematic analysis of the data revealed constraints around promotion policy and the value accorded to research development over teaching development, the inability of rural institutions to attract and retain staff, as well as the huge workloads that consumed time that could have been used for professional development. The study recommends reconsideration of theoretical frameworks that inform professional development in rural universities and a re-look at practicalities in the modes of delivery when planning for professional development interventions in rural settings.

Keywords: university teacher, rurality, professional development, agency, culture, structure

\section{INTRODUCTION}

This article stems from an eighteen-member, multi-institutional project entitled The interplay of structure, culture and agency: Contextual influences on the professional development of academics as teachers in higher education in South Africa. This study was undertaken in eight 
universities from 2011 to 2014. Among the participating institutions were three rural-based universities, one historically advantaged and two historically disadvantaged. This particular aspect of the study isolates two historically disadvantaged rural universities, given that the combination of being rural and historically disadvantaged presents particular experiences with regard to the professional development of university teachers. Since rurality and disadvantage were the focus of the sub-study, the third historically advantaged rural-based university could not be included in this case study.

The provision of high-quality teaching and learning has been recognised as a key responsibility of university teachers. While professional development in teaching practice was not previously regarded as a priority for academic staff in higher education, more recently there have been a number of policy initiatives, both internationally (Australian Teaching and Learning Council 2010) and in South Africa (Scott, Yeld and Hendry 2007) for professional development to improve teaching, learning and assessment in higher education. A number of studies argue that the increasing complexity of the academic environment requires greater levels of professional development support than previously provided (Bamber 2002; Malcom and Zukas 2001; Sorcinelli and Austin 2006). This call for university teachers' professional development is prompted by the changing situations in which universities find themselves: the increase in higher education enrolments due to equity policies has resulted in greater diversity among student populations worldwide (McNay 2005); the nature and function of higher education institutions have changed (Barnett 2005); there is a greater variety of roles required of higher education practitioners (Harris 2005; Trowler 2001), and a greater demand for accountability and professional accreditation (Nixon, Marks, Rowland and Walker 2001).

In South African universities, almost two decades after democracy, there are significant demographic changes in student populations. In particular, there has been an increase in the number of enrolments, while many students, as a direct consequence of the policies of the past, are under-prepared for tertiary studies (Soudien, Kallaway and Breier 2006). These issues underline the need for a contextually sensitive approach to the professional development of teaching academics. Since universities are differently positioned, it is of value to research how a rural context might shape appropriate staff development.

There are a number of formal professional development programmes offered in South African higher education institutions. These programmes tend to be provided by centralised education development support units (or, in the case of formal qualifications, in collaboration with faculties or academic Departments of Education). There are also a number of non-formal, research- or project-based staff development initiatives that reflect the diverse missions and 
cultures of institutions and departments (Winberg 2008; Jawitz 2007). In this particular study, professional development refers to formal and non-formal interventions organised internally and externally, in the form of programmes, courses, workshops, seminars and colloquia.

This study explores how the rural context influences academics to participate in professional development in order to enhance their own teaching. Academics cannot be understood as isolated entities but always as 'linked through a network of resources and practices that help to define individuals within their contexts' (Van Schalkwyk, Leibowitz, Herman and Farmer 2015, 5). Rurality, as a lens, promises to unveil both the peculiarity of the impediments imposed and the possibilities for professional development offered by the rural context.

\section{THE RESEARCH SETTING}

This article is based on data collected from a case study of two historically disadvantaged institutions (HDIs) identified here as A and B. Institution A is a traditional, merged institution with three campuses, two of which are located in metropolitan areas while the main campus is in a rural area. The majority of the student population is drawn from rural communities in Africa, and the majority of the students and staff are based on the main, rural campus. Most of the students are also from low to middle socio-economic backgrounds, and are funded through bursaries and scholarships intended for such socio-economic groupings. Institution B is a comprehensive institution, has only one campus and also draws most of the students from previously disadvantaged rural schools across Africa. Since there could be concerns about resources, management and cultures due to historical legacies (Badat 2012), our concern is whether rurality and the historical disadvantage nexus could influence professional development of university teachers in these contexts. We are aware that there could be common challenges and enablements in both HAIs and HDIs with regard to professional development of teachers, and that looking only at historically disadvantaged universities constitutes a limitation of the study. However, we contend that the mere location of some higher education institutions in rural settings presents unique circumstances with regard to teaching, learning and the professional development of teachers.

\section{THE CONCEPT OF RURALITY}

The concept of rurality is interpreted differently in various disciplines. On one hand, rurality is conceptualised as generative and transformative in nature in relation to the effectiveness of intervention programmes (Balfour, De Lange and Khau 2012). The generative view moves 
away from too much emphasis on the deprivation and deficiency, isolation and backwardness associated with rurality. It advocates for the acknowledgement of interactions and dynamic interplay between forces, agencies and resources. These authors further argue that the effectiveness of resources is dependent on the influence of agencies and forces. An alternative view is suggested when rurality is formulated in comparison to the urban, with strong assumptions of difference and deficit underpinning this binary (Welch, Helme and Lamb 2007; Masinire, Maringe and Nkambule 2014). Even though there is poverty in the urban context, the fact is that there is better support and infrastructure and a better chance of obtaining assistance (in the form of social services) than in rural areas. Such support is often either absent or inaccessible in rural areas owing to distance, poor transportation and neglect (HSRC 2005). In South Africa, however, the notion of rurality is closely associated with histories and structures that have created conditions and circumstances of 'oppression', 'deprivation', 'disadvantage' and 'deficit' among social groups and where resources were inadequately provided (DHET 2013). Even after twenty years of democracy, the remnants of apartheid remain and people's experiences in rural communities are undesirable because of isolation, neglect and poor resource provisioning (HSRC 2005).

The nexus between academic professional development and the rural context warrants attention, since sites used for delivering academic professional development undoubtedly influence its uptake (Mitchell 2013) and the same may be true of rurality as context and delivery site for academic development. Tytler, Symington, Darby, Malcom and Kirkwood (2009) note that there is a challenge in providing professional development for science and mathematics educators in Australia, arguing that the communities of practice model was inadequate to meet their individual needs because of distance and the isolation of teachers. Geographic and social isolation are linked to professional isolation and lack of professional support from mentors, colleagues and counterparts (Mills and Millsteed 2002; McCoy 2009). In these rural contexts there are also the challenges of demanding workloads and multiple duties, which militate against the uptake of professional development (Mollenkopf 2009).

Other studies suggest that the quality of professional development is mediated by the environment, and that professional development practices in rural contexts are influenced by socio-economic factors (Supovitz and Turner 2000). Though rurality presents an opportunity for the use of online formats in the delivery of professional development courses to compensate for geographic and professional isolation, there is often the challenge of technical and professional support for the smooth operation of online platforms (Mollenkopf 2009). These factors require careful consideration when planning professional development activities in rural 
contexts.

\section{ARCHER'S SOCIAL REALIST THEORY}

This study makes use of the social realist framework and draws heavily on Margaret Archer's work (1995; 2000; 2007), particularly on the interplay of structure, culture and agency. The value of the social realist theory lies in its parallel with a generative theory of rurality (Balfour, Mitchell and Moletsane 2008), which emphasises the semblance and confluence of forces, agencies and resources as components and explanations for experiences, context and social issues in rural settings. Thus, connections can be made between the social realist framework and the generative theory of rurality, which both emphasise agency in the mediation of both the enabling and constraining factors as they relate to professional development in rural contexts.

According to Archer (2000), structure refers to the social arrangements, power relations and resources available in any context. For instance, heavy workloads can be viewed as a structural constraint since they involve structures and authority such as workload policy and are dependent on resources. Inadequate human resources, due to inability to hire more staff as a result of inadequate financial resources might result in heavy workloads for few available staff.

The cultural milieu comprises values, beliefs, attitudes, ideologies and practices (Archer 2000). Culture in higher education contexts can be accommodating or hostile to particular teaching and learning practices and to the motivation to enhance teaching practice and develop professionally (Leibowitz, Van Schalkwyk, Van der Merwe, Herman and Young 2009). For instance, little or no enforcement or encouragement to take academic professional development will probably impact negatively on uptake.

Agency refers to the personal powers in the form of decision-making, dispositions to act, and the exercise of the will. It relates to the social roles of people and the choices they make when acting out their roles (Archer 2000). For instance, the decision to take up professional development may mean that those who go for staff development voluntarily are those who perceive the need for development. Studies have shown that despite prevailing cultures and structural constraints, some staff go against the odds and develop themselves professionally (Barley and Beesley 2007).

\section{RESEARCH DESIGN}

This article draws qualitative data from a multiple case study of the two rural universities that served as cases. They are both historically disadvantaged as well as being located in rural settings, and this presents unique insights with regard to the professionalisation of teaching. 
Two data sets were used, namely, document analysis and analysis of interview transcripts.

As part of the study, each institution was asked to produce two documents: one document gave a brief description of the institution, including how professional development was described in institutional documents, and the second document contained a reflective discussion of the conditions, activities and impact of the professional development unit/centre for teaching and learning. This document was compiled by the head of the relevant teaching and learning unit/centre. Attached to each institution's report were appendices which included, but were not limited to staff development policies, teaching and learning policies and strategic plans.

The interview sample in each case comprised fifteen staff members, five of whom were members of senior management and ten of whom were academics. The senior management comprised the vice-chancellor, deputy vice-chancellor responsible for teaching and learning, and three deans from various faculties. Members of senior management were purposively selected, since as institutional academic managers, they were regarded as having an understanding of policy as well as practical experience of issues of professional development for university teachers. Given the need to ensure credibility and trustworthiness (Creswell 2009), the interviews were tape-recorded in order to capture the conversations in full. Content analysis was used to identify emerging themes from interview transcripts and institutional documents. Written ethical clearance was obtained from the two institutions.

\section{RESULTS OF THE STUDY}

The results of the study are analysed under the following main headings:

- how professional development is described at the institutions,

- $\quad$ how professional development is promoted at the institutions, and

- $\quad$ constraints experienced in the promotion of professional development.

\section{How senior management viewed professional development}

For some members of senior management, professional development was seen in terms of advancement in qualifications in one's discipline. From the excerpts of the participants below, the impression is that few staff at these universities had attained doctoral qualifications in their disciplines. As these are historically disadvantaged and rural universities, this could be because, historically, fewer staff had postgraduate qualifications. So the emphasis is on qualifications rather than on teaching and learning. The response from Institution A shows that, even at academic management level (HOD), there were staff members without a Master’s degree: 
You want to make sure that you grow a calibre of people through their Honours and Masters and PhDs ... (Senior manager at University B).

I would like to see that all my HODs are on a Masters level, you know. (Senior manager at University A).

This particular position on staff development, where emphasis is on academic qualifications rather than teaching and learning qualifications, is structural and based on the legacy of apartheid structural constraints. Lecturers say they have no time for professional development programmes as they are fully occupied with academic studies. As there is pressure to upgrade their academic qualifications, it seems that priority is given to the pursuit of academic qualifications rather than professional development.

For me, the thing is, I need to complete my thesis and if I have any spare time, it should be focused on that and I can do the rest afterwards. (Lecturer at University A).

I need to grow by research; I need to grow by doing my $\mathrm{PhD}$ and other things. (Lecturer at University B).

Both responses demonstrate that growth was seen only in terms of research and upgrading one's qualifications and, by implication, not by developing in the field of teaching.

There was also mention of professional development with regard to the lecturers' teaching roles in the senior management responses. Senior managers stressed the need for academics to hold appropriate teaching qualifications:

First of all, I would like to see more of our staff members get a teaching qualification. Very, very few of them have a diploma in tertiary education ... (Senior manager at University B).

Professor $\mathrm{H}$ is currently on the program (PGDHET) and we have urged other staff members to enroll. They have all expressed their desire to join and enroll for the program. (Senior manager at University A).

The views above support the notion that highly qualified staff are able to carry out their professional tasks competently. However, there may not always be a positive and inextricable relationship between possessing high qualifications and performing well professionally. The institutional milieu (in the domain of culture) may affect the level of motivation to perform at the expected level. In this light, management expectations of excellent performance by highly qualified staff may be undermined by poor morale and unfavourable working environment. As Leibowitz $(2016,207)$ argues, 'If national policy makers or university senior managers wish to influence academics' motivation to teach via extrinsic means such as policy on the recognition 
of good teaching or career pathing in relation to the teaching function, they should ensure that environmental conditions support these extrinsic measures'.

\section{HOW LECTURERS VIEWED PROFESSIONAL DEVELOPMENT}

For some lecturers, professional development was understood as getting information that would assist them in their teaching and to resolve issues they could not otherwise deal with in the lecture room. This seemed to be driven by personal agency to improve professional practice (Zimmerman and Schunk 2008) and seems particularly evident at Institution B, as shown in the following statement from the institutional reflective report:

On the whole, staff development initiatives in the institution appear to have been mainly voluntary and dependant on individual department and lecturer's interest.

Secondly, responses seemed to indicate that professional development entails engaging in scholarly acts. This implies that teaching ought to be grounded in strong theoretical foundation and best teaching practice, and this practice should be shared with other stakeholders in the field, who comment on the relevance of the practice to the requirements of the discipline (Clegg 2009). For one to engage in scholarly teaching, there is a need to continually find innovative ways of teaching, apart from those one already knows:

You know, you really feel like you have something to offer and then you begin over the course of years to really realize how much you still need to learn, ways you still need to grow and ways that you can make learning more exciting to your students. (Lecturer at University A).

Thirdly, the lecturers also believed that professional development required the teacher to have a personal motivation to be involved in it:

... All of the staff members in my department, that have done this course or are doing this course, they're all sort of self-regulated and prepared to give that time up. (Lecturer at University A).

What actually pushed me was seeing that sometimes students needed help that I may not be able to offer them. (Lecturer at University B).

\section{HOW PROFESSIONAL DEVELOPMENT IS PROMOTED BY MANAGEMENT}

The responses indicated that support was provided in various forms, depending on each executive manager's personal views. Some of the managers used one-on-one consultations as platforms for understanding issues that hindered good teaching by subordinates, as well as to plan appropriate staff development interventions. Others provided financial resources for professional development, encouraged their staff to participate in professional associations and 
to share knowledge with the wider world through conferences and colloquia:

I develop that person ... I meet one-on-one with staff, so that we talk about where you're going and how things are going. (Senior manager at University A).

Staff members are allowed some time off to attend a lesson or two ... also we allow people to attend workshops and conferences, we make funding available for them to do that. (Senior manager at University B).

One of the managers at University A was of the opinion that professional development could be promoted by providing opportunities for staff to showcase best practice in their professional duties. This was corroborated by the director of the Teaching and Learning Centre (TLC) at the same institution:

For the first time ever this year we are going to have a teaching and learning week where we showcase the work that we do ... We are inviting faculties to showcase their work, to say that 'I have this project and the theme is large classes, dealing with large classes in the twenty first century' (Director of teaching and learning at University A).

... (W)e don't showcase the good things that are happening ... the good thing about doing that is that once people know and they hear regularly the good things, then people are encouraged to look for more good things out there ... (Senior manager at University A).

Because members of management viewed professional development mainly as advancement in qualifications in one's discipline, when asked how they promoted professional development they indicated that they encouraged staff to take higher degrees such as Master's and doctoral studies as a way to bolster staff capacity:

Our idea (and the Vice Chancellor's vision) is that in the next five years close to $75 \%$ of our staff members here should have a PhD. (Senior manager at University A).

One other area which is ongoing and it's a long term objective, is the upgrade of qualifications of staff members ... particularly the doctoral degree ... (Senior manager at University B).

The views of management seem to suggest that staff who pursue higher degrees advance their own knowledge, competencies and experiences. This, in turn, improves the productivity of their work. In this instance, the higher education practitioners who advance qualification-wise are able to use innovative teaching strategies to improve the quality of learning, retention and throughput. The two universities have, in terms of social realist theory, created structures that enable academics to pursue professional development opportunities. However, structure alone cannot result in staff undertaking these opportunities. As Sayer (1992) shows, structures may mediate, but they do not determine what the agents do. The academics must exercise their 
agency by taking up these opportunities and if they do not, there is not much more the university can do, as shown in the following management response:

So if the university has created the environment, because I think that is the main thing that we can do, to create the environment for people to develop themselves. But if they don't do it themselves, then there is not much that can be done to help them. (Senior manager at University A).

\section{How professional development is promoted}

Lecturers also perceived professional development as promoted through structural support in the form of professional development courses, funding for studies and opportunities to attend conferences to share best practice with their counterparts at other institutions. Lecturers felt that there was enough support to engage in professional development opportunities, provided by their heads of departments, deans and the Centre for Teaching and Learning. Thus, 'for anything to exert the power of a constraint or an enablement, it has to stand in a relationship such that it obstructs or aids the achievement of some specific agential enterprise' (Archer 2003 cited in Crawford 2010, 191). In this instance, the availability of support structures aided the agential enterprise of engaging in professional development, as is shown in the quotes below:

... a very good initiative from TLC (to conduct workshops), because ... a lot of the topics that were scheduled, were very pertinent and topical. Like how to deal with big classes and e-learning and all of that ... (Lecturer at University A).

Firstly, the establishment of the centre itself is one mechanism. The university has decided that it establishes a dedicated hub from where all the initiatives on staff development will be driven from. (Lecturer at University B).

The main driver for professional development at Institution A, according to the lecturers, seemed to be the policy on promotion. This was raised by both lecturers and the director of the teaching and learning centre. The issue was also captured in Institution A's reflective report. Thus some staff members simply engaged in these professional development opportunities, not necessarily to empower themselves, but to meet institutional compliance requirements such as the criteria for promotion, as illustrated in the following:

And specifically, in terms of promotion, we have to have the assessment and moderation component. (Lecturer at University A).

That particular module (the assessment module), started out as something that is an imposition... It was said all lecturers should do that and if you don't do that particular module, forget about applying for promotion. (Lecturer at University A).

According to Crawford's study (2010), there was broad agreement that institutional strategies 
had limited influence across the academic body, but in this study this does not seem to be the case. The institutional strategy of tying promotion to the attainment of a qualification in assessment had a huge influence on the numbers that enrolled for the assessment course compared to other courses that were not compulsory, as shown in Institution A's self-reflective report:

In 2010, 40 academics registered and completed the Assessment module offered as a Continuing Education (CE) course. Other CE enrolments in 2010 were three participants for the Nature of Learning module of which two passed the course. It's compulsory that an academic provides evidence of having passed the Assessment course at NQF 7 before being considered for promotion. This explains why there have been quite a number of academics enrolling for the Assessment module. (Institution A, report).

The views from staff and the self-reflective report above (in relation to promotion) seem to suggest that they were taking up staff development opportunities to safeguard their job security and because they were instructed to do so, rather than as part of a personal development plan. While on one hand this approach fulfils the objective of having staff who would otherwise not attempt to develop themselves professionally, on the other hand this approach involves the risk of having people who still perform poorly even after attaining professional qualifications. This tendency to force academics to attend professional development courses in teaching is corroborated by Amundsen and Wilson (2012, 90), who note that, 'Some long-standing assumptions in higher education are that academics are not adequately prepared for their teaching role, have unsophisticated conceptions of teaching and learning, and have little knowledge of effective teaching practices, both in general and in their own specific discipline'.

\section{CONSTRAINING CONDITIONS IN THE UPTAKE OF PROFESSIONAL DEVELOPMENT}

Even with the provision of funding for professional development, clear understanding and communication with regard to eligibility seemed to be lacking at Institution A, particularly among new staff. This lack of clarity resulted in some academics paying for the courses and programmes themselves. Some staff members were uncomfortable with having to do this, since, officially, the university was supposed to pay. This suggests a lack of clarity concerning the staff subsidy. Perhaps awareness workshops are needed, especially for new staff, so that their interest in professional development can be promoted. However, this problem seems to be peculiar to only one institution, as it did not arise from analysis of the data from the other seven universities that participated in the multi-case study.

Two lecturers at Institution A believed that the concept of staff development was not well 
understood due to lack of alignment between individual needs and institutional requirements:

... (I)t is only when we align and recognize that the institutional interests and individual interests are aligned and they become one, then we start to talk about what we call staff development. (Lecturer at University A).

The support is not structured and it is not focused on the actual needs of the person involved in staff. (Lecturer at University A).

'Processes, policies and priorities, which are experienced as being misaligned, can have negative influences on academics' attitudes and behaviours in respect of their development' (Crawford 2010, 196). As Crawford's study (2010) and the quotations above show, perceived incompatibility and lack of correlation between institutional and individual priorities are particularly constraining.

The responses from management, academics and directors of the TLCs at the two institutions also indicated that the institutions were struggling to recruit qualified staff in some of the departments. The fact that only one-third of the academic staff at Institution B had doctoral qualifications (Institutional report, Institution B) implied that staff in most departments felt overwhelmed by the need to upgrade their qualifications. At Institution B, for example, the institutional reflective report states that the average staff-student ratio is 40 to one and, 'The student numbers have doubled in the past five years while instructional staff did not increase'. Similarly, Leibowitz, Bozalek, Van Schalkwyk and Winberg (2015) also noted that the average staff-student ratio at historically disadvantaged universities is 40 students per lecturer compared to nineteen students per lecturer at historically advantaged universities. This impairs the ability and enthusiasm to engage in professional development opportunities:

In fact, that's probably at the bottom of it all ... it's difficult to obtain the proper numbers of staff. (Senior manager at Institution A).

The above findings are similar to Mollenkopf's observation (2009) that multiple duties and demanding workloads negatively affect the uptake of professional development in rural contexts. Similarly, Laurillard (2002) is of the view that academic staff members at universities have competing and equally demanding responsibilities in teaching, research and community engagement, which leaves them with very little, if any, time for extra demands such as undertaking professional development courses. As the situation seems worse at historically disadvantaged, rural universities, 'a concern for equity and social justice should remain a dominant element in discourses about higher education learning and teaching enhancement in South Africa - as well as elsewhere in the world’ (Leibowitz et al. 2015, 328). 
The issue of the inability to attract staff because of the rural context (which is a structural constraint) is further foregrounded by the directors of the TLCs at the two institutions. The TLC director at Institution B noted,

Sometimes, because of this inability to attract (staff), there is inadequate staff in the faculties and they have to take on extra work.

Using the TLC as an example at Institution B, the director went on to say:

My own post of director here was advertised three times before the university could fill it.

When asked why it took so long to fill the post, he responded: '.. because of the location of our university. Most people are attracted by the city lights.' In the same vein, the director of the TLC at Institution A noted:

When I arrived I realized that there has been a high staff turnover within the unit (TLC) and I'm reliably told that that has been the trend even within the university, staff don't necessarily find the XXX Campus to provide a quality of life because it's a rural campus ... the town is small, it's rural, you know ...

The poor rural conditions mentioned above, that discouraged academics from taking up positions at these institutions, were exacerbated by the poor teaching conditions that generally prevailed. Basic facilities were said to be lacking in lecture rooms at both institutions, as indicated by the following quotes:

... like the lecture venues that aren't, you know, that don't support a projector, ... in the absence of a microphone I end up circling the lecture venues, so that everybody can get to hear me at some point in time. (Lecturer at University A).

The infrastructure is not really up to date. There are no screens to project onto - if you don't have proper or adequate classrooms; if you don't have the necessary equipment - those things may really impact very badly on the teaching. Certain things ... maintenance has not been done here and there, and so on. (Lecturer at University B).

Rurality, therefore, seemed to discourage academics from taking up positions at these institutions. In this regard, Leibowitz et al. $(2015,321)$ aver that, 'Institutional contextual differences in relation to history, geographical location and resource allocation affect the institution's ability to attract and retain academic staff, and in this way, impact on teaching quality’.

The multi-campus environment at Institution A, together with the shortage of technologyrelated resources, was also seen as a constraint related to the uptake of professional 
development. Movement of staff from one campus to another was a tiring process for those who had to work in various campuses. Time used for travelling between campuses could have been used for professional development opportunities. The response below shows that the shortage of resources results in time-wasting through inter-campus travel:

If we had enough resources, like video conferencing and a lot of those things were working fairly well, I think we could eliminate what I am going to say, which is the time, because having to drive to Town A, I always feel it's a waste of my time. Lecturer at University (A).

\section{THE STATURE OF TEACHING AS A CONSTRAINT TO PROFESSIONAL DEVELOPMENT}

With regard to the status of teaching at the university in relation to professional development, both members of senior management and academics felt teaching was held in lower esteem than research. It also emerged from both lecturers and senior management that because research was held in such high esteem, senior academics were assigning junior classes, which are usually larger, to junior staff, in order to give themselves enough time to engage in research, as expressed below:

I see it and I worry about it, that our professors and senior lecturers, who should be the ones involved with the first-year students, pass it on to the junior staff because they are too busy with research and with their postgraduate students. (Lecturer at University A).

Even the one now (teaching development workshop held recently), I was supposed to be there, but I had to go to a paper-writing retreat. So I was writing papers for publication ... (Lecturer at University B).

The foregrounding at the two institutions of research at the expense of teaching and learning seems ironic, given that the vision and mission statements of the two universities did not foreground research as the main focus, but rather sought to strike a balance between the teaching and research. According to Institution A's institutional reflective report, the vision of the university is given as, 'A vibrant, equitable and sustainable African university, committed to teaching and research excellence at the service of its students, scholars and the wider community'. The mission of Institution B, according to the institution's reflective report, is expressed as: '... a comprehensive institution, The University ... offers a range of undergraduate and post-graduate qualifications in fields of study that are responsive to the development needs of the Southern African region, using appropriate learning methodologies and research.' Neither of these statements implies that the two institutions seek to be recognised primarily as research-intensive institutions. This points to a misalignment between the espoused intentions and priorities of the institutions, and what is actually practised at them. 
While this study concentrated on rural, historically disadvantaged universities, similar findings on the issue of research versus teaching are also reported from an urban, formerly historically advantaged university, by Jawitz and Perez (2015). According to these authors, at the historically advantaged urban university which they studied, the research emphasis was entrenched by the way in which academic salaries were constructed; the only opportunity for a salary increase was through promotion, and here publishing took priority. This implies that 'spending time on professional development for teaching rather than research can involve the risk of limiting earning potential and career advancement' (Jawitz and Perez 2015, 8). In the same vein, Steel (2004) contends that apart from academic pressures, lecturers' resistance to undertaking professional development courses was a result of undervaluing teaching and learning among their core duties. The 'research versus teaching' issue therefore does not seem to be confined to rural areas but is perpetrated across contexts.

\section{CONCLUSIONS OF THE STUDY}

The study concludes that the dual characteristics of rurality and disadvantage pose challenges as well as very few enablements for the professional development of academics in rural contexts. The results show that structural issues such as policy on promotion influence the uptake of professional development. The uptake of developmental opportunities is militated against by some facets of rurality, such as huge workloads due to the inability to attract staff to these less attractive places (structure), poor resources and the low status of teaching in relation to research (culture) and academics own lack of volition to undertake professional development (agency).

This article has shown that structure and culture provide enablements and/or constraints to which academics may respond, depending on how they exercise their individual agency. Agentic factors might mean going against the norm and not being influenced by external factors when taking up professional development opportunities. The decision to make use of a staff development opportunity might imply interplay between culture and agency. For instance, Crawford (2010) investigated the interplay between structure and agency in two universities in the United Kingdom and found three key tensions in the educational context: the significance of professional status (culture: in our case the influence of the valuing of research over teaching); the influence of misaligned initiatives and priorities (structure: in the example from this article influence of promotion policies on uptake); and the influence of supportive networks (collective agency). Thus, the interplay of structure, culture and agency is not linear and unidirectional, but intersectional and interactional. The study reported in this article confirms 
the relevance of Crawford's findings (2010) to the South African context.

\section{RECOMMENDATIONS}

The perceptions of motivating academics to engage in professional development, as shaped by rurality, need to be framed and focused so that they do not lead to inactivity with regards to the uptake of opportunities. The dispositions of teaching academics towards professional development could be influenced positively if academics were sensitised and oriented towards alternative ways in which professional development is offered. These require online platforms; technical and administrative support should be provided to guarantee effectiveness and continuance.

Institutional policies and strategies on teaching development of university teachers therefore need to campaign for, frame and focus on rurality. Furthermore, the professional development of managers and academic developers should, as a matter of urgency, focus on ways of mitigating the challenges imposed by rurality, particularly those relating to geographical and professional isolation.

There might be a need for context-specific professional development, especially informally. For instance, to incentivise staff members who make an extra effort to support innovative teaching through their own development, either formally or informally, could boost morale.

There is also a need for reconsideration of the theoretical frameworks that undergird professional development models. Models for professional development in rural contexts need to take into account resource constraints as well as geographical and professional isolation. Practical issues associated with the planning for professional development interventions in rural contexts need to be negotiated.

Finally, since the NRF multi-case study's focus was not specifically on rurality but across rural and urban contexts, we recommend a further, in-depth study into how rurality influences teaching and learning, how rurality acts as a constraint and how some of the conditions underpinning rurality could be turned into advantages.

\section{ACKNOWLEDGMENTS}

The National Research Foundation provided funding for the project titled Context, structure and agency (grant number 74003). We also acknowledge contributions to the data by the members of the Context, Structure and Agency research team. 


\section{REFERENCES}

Amundsen, C. and M. Wilson. 2012. Are we asking the right questions? A conceptual review of the educational development literature in higher education. Review of Educational Research 82(1): 90-126.

Archer, M. S. 1995. Realist social theory: The morphogenetic approach. New York: Campbridge University Press.

Archer, M. S. 2000. Being human: The problem of agency. New York: Cambridge University Press.

Archer, M. S. 2003. Structure, agency and the internal conversation. New York: Campbridge University Press.

Archer, M. S. 2007. Contributions to social ontology. London and New York: Routledge.

Australian Learning and Teaching Council. 2010. Learning and Teaching Academic Standards Project: Creative and performing arts, learning and teaching academic standards statement. Sydney, Australia: Australian Learning and Teaching Council.

Badat, S. 2012. Redressing the colonial/apartheid legacy: Social equity, redress, and higher education admissions in democratic South Africa. In Equalizing access: Affirmative action in higher education in India, United States, and South Africa, Eds. Z. Hasan and M. Nussbaum, 121-150. New Delhi: Oxford University Press.

Balfour, R. J., N. de Lange and M. Khau. 2012. Rural education and rural realities: The politics and possibilities of rural research in Southern Africa. Perspectives in Education 30(1): i-ix.

Balfour, R. J., C. Mitchell and R. Moletsane. 2008. Troubling contexts: Toward a generative theory of rurality as education research. Journal of Rural and Community Development 3(3): 95-107.

Bamber, V. 2002. To what extent has the Dearing policy recomendation on the training of new lecturers met acceptance? Where Dearing went that Robbins didn't dare. Teacher Development 6(3): 433458.

Barley, Z. A. and A. D. Beesley. 2007. Rural school success: What can we learn? Journal of Research in Rural Education 22(1): 1-16.

Barnett, R. 2005. Reshaping the university: New relationships between research, scholarship and teaching. 1st Ed. Buckingham: Open University Press.

Soudien, C., M. Breier and P. Kallaway. 2012. Education, equity and transformation. London: Springer Science \& Business Media.

Clegg, S. 2009. Forms of knowing and academic development practice. Studies in Higher Education 34(4): 403-416.

Crawford, K. 2010. Influences on academics' approaches to development: Voices from below. International Journal for Academic Development 15(3): 189-202.

Cresswell, J. W. 2009. Research design. Qualitative, quantitative and mixed method approaches.Thousand Oaks: SAGE.

Department of Higher Education and Training. 2013. White Paper on Post-School Education and Training. DHET: Pretoria, South Africa.

Harris, S. 2005. Rethinking academic identities in neoliberal times. Teaching in Higher Education 10(4): 421- 433.

HSRC see Human Sciences Research Council.

Human Sciences Research Council. 2005. Emerging voices: A report on education in South African rural communities. Nlelson Mandela Foundation, Cape Town: Human Sciences Research Council.

Jawitz, J. 2007. New academics negotiating the communities of practice: Learning to swim with the big fish. Teaching in Higher Education 12(2): 185-197. 
Jawitz, J. and T. Perez. 2015. Investing in teaching development: Navigating risk in a research intensive institution. International Journal for Academic Development 1-12. DOI:10.1080/1360144X.2015.1081852

Laurillard, D. 2002. Rethinking university teaching: A framework for effective use of educational technology. London: Routledge.

Leibowitz, B. L. 2016. Professional academic development - the influence of context on motivation. South African Journal of Higher Education 30(6): 193-208.

Leibowitz, B., S. van Schalkwyk, A. van der Merwe, N. Herman and G. Young. 2009. What makes a 'good' first-year lecturer. In Focus on first year success: Perspectives emerging from South Africa and beyond, ed. B. Leibowitz, S. van Schalkwyk and A. van der Merwe, 255-270. Stellenbosch: Sun Media.

Leibowitz, B., V. Bozalek, S. van Schalkwyk and C.Winberg, 2015. Institutional context matters: The professional development of academics as teachers in South African higher education. Higher Education 69 (2):315-330.

Malcolm, J. and M. Zukas. 2001. Bridging pedagogic gaps: Conceptual discontinuities in higher education. Teaching in Higher Education 6(1): 33- 42.

McCoy, C. 2009. Professional development in rural nursing: Challenges and opportunities. Journal of Continuing Education in Nursing 40(3): 128-131.

McNay, I. 2005. Beyond mass higher education. London: Open University Press.

Masinire, A., F. Maringe and T. Nkambule. 2014. Education and rural development: Embedding rural dimension in teacher initial preparation. Perspectives in Education 32(3): 146-158.

Mills, A. and J. Millstead. 2002. Retention: An unresolved workforce issue affecting rural occupational therapy services. Australian Occupational Therapy Journal 49: 170-181.

Mitchell, R. 2013. What is professional development, how does it occur in individuals, and how may it be used by educational leaders and managers for the purpose of school improvement? Professional Development in Education 39(3 ): 387- 400.

Mollenkopf, D. L. 2009. Creating highly qualified teachers: Maximising university resources to provide professional development in rural areas. Rural Educator 30(3): 34-39.

Nixon, J., A. Marks, S. Rowland and M. Walker. 2001. Towards a new academic professionalism: A manifesto of hope. British Journal of the Sociology of Education 22(2): 227-244.

Sayer, A. 1992. Method in social science: A realist approach. London: Routledge.

Scott, I., N. Yeld and J. Hendry. 2007. A case for improving teaching and learning in South African higher education. Pretoria: Council on Higher Education.

Sorcinelli, M. D. and A. E. Austin. 2006. Developing faculty for new roles and changing expectations. Effective Practices for Academic Leaders 1(11): 1-16

Steel, C. 2004. Establishing a zone where technology innovation is supported. In: Beyond the comfort zone: Proceedings of the $21^{\text {st }}$ Ascilite Conference, ed. R. Atkinson, C. Mc-Beath, D. Jonas-Dwyer and R. Phillips, 865-874. Perth, 5-8 December.

Supovitz, J. A. and H. M. Turner. 2000. The effects of professional development on science teaching practices and classroom culture. Journal of Research in Science Teaching 37(9): 963-980.

Tytler, R., S. David, L. Darby, M. Cliff and V. Kirkwood. 2009. Discourse communities. A framework to consider professional development for rural teachers in science and maths. Teaching and Teacher Education 27: 871-879.

Trowler, P. 2001. Captured by the Discourse? The Socially Constitutive Power of New Higher Education Discourse in the UK. Organization 8(2): 183-201.

Van Schalkwyk, S., B. Leibowitz, N. Herman and J. Farmer. 2015. Reflections on professional learning: Choices, context and culture. Studies in Educational Evaluation 46: 4-10. 
Welch, A., S. Helme and S. Lamb. 2007. Rurality and inequality in education: The Australian experience. In International studies in educational inequality, theory and policy. Inequality in education systems, ed. R. Teese, S. Lamb, M. Duru-Bellat, 271-293. Dordrecht: Springer.

Winberg. 2008.Teaching engineering teaching: Interdisciplinary collaboration and construction of academic identities. Teaching in Higher Education 13(3): 353-367.

Zimmerman, B. and D. H. Schunk. 2008. Motivation: An essential component of self regulated learning. In Motivation and self regulation learning theory, research and practice, ed. B. Zimmerman and D. H. Schunk, 1-30. New York: Lawrence Erlbaum. 